УДК 661.183 .2

\title{
ИССЛЕДОВАНИЕ ТЕРМОЩЕЛОЧНОЙ АКТИВАЦИИ ЛИГНИНА ИЗ СОЛОМЫ ПШЕНИЦЫ, СТРОЕНИЯ И СВОЙСТВ ПОЛУЧАЕМЫХ
} АКТИВНЫХ УГЛЕЙ

\author{
() Н.М. Микова ${ }^{1}$, И.П. Иванов ${ }^{1}$, Н.В. Чесноков ${ }^{1,2}$, Б.Н. Кузнецов ${ }^{1,3^{*}}$ \\ ${ }^{1}$ Институт химии и химической технологии СО РАН, ул. К. Маркса, 42, \\ Красноярск, 660049 (Россия), e-mail: inm@icct.ru \\ ${ }^{2}$ Красноярский научный центр СО РАН, Красноярск (Россия) \\ ${ }^{3}$ Сибирский фредеральный университет, пр. Свободный, 79, Красноярск, \\ 660041 (Россия)
}

Изучено влияние условий термообработки лигнина, выделенного из соломы пшеницы, на структуру и адсорбционные свойства получаемых углеродных материалов (УМ). Термоактивация лигнина КОН и $\mathrm{NaOH}$ способствует развитию удельной поверхности получаемых УМ до $2680 \mathrm{~m}^{2} /$ г и пористого объема до 1,35-1,39 см $3 /$ г. Предварительная карбонизация лигнина при $800{ }^{\circ} \mathrm{C}$, предшествующая активации щелочами, несколько снижает удельную поверхность (до $\left.2000 \mathrm{~m}^{2} / \Gamma\right)$, но способствует формированию микропористых УМ с узким распределением пор по размерам (1,71,9 нм). Полученные УМ обладают высокой сорбционной активностью по отношению к бензолу и водороду.

Ключевые слова: лигнин соломы, карбонизация, щелочная активация, углеродный материал, пористость, адсорбционные свойства.

\section{Введение}

Лигнин - второй (после целлюлозы) по значимости натуральный природный полимер ароматического типа, содержащийся в лигноцеллюлозной биомассе. Лигнин имеет высокое содержание углерода и молекулярную структуру, подобную бурому углю, и может использоваться в качестве сырья для получения углеродных материалов и адсорбентов [1-5].

Показана возможность формирования микропористых углеродных материалов с удельной поверхностью около $350 \mathrm{~m}^{2} / \Gamma$ при карбонизации гидролизного лигнина при температурах 600-900 ${ }^{\circ} \mathrm{C}$. Для даль-

Микова Надежда Михайловна - старший научный сотрудник, кандидат химических наук, e-mail: nm@icct.ru

Иванов Иван Петрович - старший научный сотрудник, кандидат технических наук, e-mail: ivanov@icct.ru Чесноков Николай Васильевич - заместитель директора Института химии и химической технологии СО РАН, заместитель председателя Красноярского научного центра СО РАН доктор химических наук, e-mail: cnv@icct.ru

Кузнецов Борис Николаевич - первый заместитель директора Института химии и химической технологии СО РАН, профессор, доктор химических наук, заведующий кафедрой аналитической и органической химии Сибирского федерального университета, тел.: (391) 249-48-94, e-mail: bnk@icct.ru, inm@icct.ru нейшего развития пористости полученного из гидролизного лигнина углеродного материала использована его активация водяным паром при $800{ }^{\circ} \mathrm{C}$, что позволило получить активные угли с поверхностью до $865 \mathrm{~m}^{2} /$ г и объемом микропор около $0,37 \mathrm{~cm}^{3} / г$ [5].

Одним из вариантов переработки лигносодержащего сырья в активные угли является термическая активация в присутствии химических соединений [68]. Путем термической активации гидролизного лигнина соединениями щелочных металлов при 500$900{ }^{\circ} \mathrm{C}$ получены активные угли с удельной поверхностью до 800-2000 м²/г [9].

При химической активации добавка щелочи усиливает реакции дегидратации, дегидрогенизации,

\footnotetext{
* Автор, с которым следует вести переписку.
} 
образования межмолекулярных связей, приводящие в итоге к конденсации ароматических фрагментов. При термообработке химически модифицированной биомассы в результате протекания окислительногидролитических превращений образуются газообразные продукты $\left(\mathrm{CH}_{4}, \mathrm{H}_{2}, \mathrm{H}_{2} \mathrm{O}, \mathrm{CO}\right.$ и др.), что способствует развитию пористой структуры УМ [10]. Действие щелочной добавки двояко: с одной стороны, она промотирует реакции расщепления имеющихся связей в трехмерной структуре, а с другой - образование новых поперечных сшивок между фрагментами биополимера, углубляя процесс поликонденсации [6, 8-9].

В настоящее время имеется только ограниченная информация о влиянии природы лигнина и условий его щелочной активации на формирование пористой структуры и сорбционные свойства активных углей. Причем в качестве объекта исследований использовались лигнины, выделенные из древесины.

В данной работе изучены особенности термощелочной активации лигнина, выделенного из соломы пшеницы, а также строение и свойства получаемых активных углей.

\section{Экспериментальная часть}

В качестве объекта исследования был использован лигнин щелочной делигнификации соломы пшеницы, измельченный до фракции 0,25-1,0 мм и высушенный до постоянного веса (элементный состав, \% вес: $\mathrm{C}-61,9 ; \mathrm{H}-5,5 ; \mathrm{N}-0,5 ; \mathrm{S}-0,2 ; \mathrm{O}-31,9$; зола - 2,5). Щелочной лигнин получали кипячением измельченной соломы (фракция 3-5 мм) в 5\%-ном растворе $\mathrm{NaOH}$ при $170{ }^{\circ} \mathrm{C}$, последующим осаждением из фильтрата $13 \%$-ным раствором $\mathrm{HCl}$, отмывкой продукта горячей дистиллированной водой $\left(50{ }^{\circ} \mathrm{C}\right)$ до нейтральной рН и сушкой.

Предварительную карбонизацию лигнина соломы (ЛС) проводили нагреванием образцов от комнатной температуры до $800{ }^{\circ} \mathrm{C}$ в атмосфере аргона со скоростью подъема температуры $1{ }^{\circ} \mathrm{C} /$ мин и выдержкой при конечной температуре 0,5 ч.

Термоактивацию образцов гидроксидами калия и натрия проводили при весовом соотношении лигнин : щелочь $1: 1-1: 4$ со скоростью подъема температуры $5{ }^{\circ} \mathrm{C} /$ мин до $800{ }^{\circ} \mathrm{C}$ и изотермической выдержкой в течение 1 ч в атмосфере аргона.

Данные о пористой структуре образцов получены из изотерм адсорбции азота при 77 К. Адсорбционные измерения проводили на объемной вакуумной статической установке ASAP 2420 Micrometrics в диапазоне относительных давлений $\mathrm{P} / \mathrm{P}_{\text {о }}$ от 0,005 до 0,995. Перед измерениями образцы предварительно тренировали при $300{ }^{\circ} \mathrm{C}$ и остаточном давлении 0,001 мм рт. ст. в течение 12 ч.

Исследование строения образцов проводили методом сканирующей электронной микроскопии (SEM) на микроскопе JSM 7001F фирмы «Jeol».

Регистрацию ИК-спектров (FTIR) образцов осуществляли на ИК Фурье спектрометре Vector 22 фирмы Bruker. Образцы для съемки готовили в виде прессованных таблеток, содержащих 2 мг образца в матрице бромистого калия.

Термогравиметрический анализ выполняли с использованием прибора «Netzsch STA 449F1» в температурном интервале от 30 до $800{ }^{\circ} \mathrm{C}$ со скорость нагрева образца $5{ }^{\circ} \mathrm{C} /$ мин в атмосфере аргона.

Оценку сорбционной активности полученных УМ по отношению к водороду проводили при 77 К под давлением $\mathrm{H}_{2}$ 6,5 МПа в течение 0,5 ч после предварительной тренировки образцов под вакуумом при температуре $300{ }^{\circ} \mathrm{C}$ в течение 2 ч и последующего охлаждения. Десорбцию водорода осуществляли в неизотермическом режиме (скорость подъема температуры $5{ }^{\circ} \mathrm{C} / \mathrm{Mин}$ ) до конечной температуры $400{ }^{\circ} \mathrm{C}$.

Сорбционную активность по бензолу оценивали по способности УМ поглощать его пары в стационарных условиях равновесного заполнения пор при $25^{\circ} \mathrm{C}$.

\section{Результаты и обсуждение}

В результате проведенных исследований было установлено, что развитие удельной поверхности активных углей, получаемых щелочной активацией лигнина, выделенного из соломы пшеницы, определяется условиями карбонизации и активации, способом введения и количеством щелочи. При карбонизации лигнина соломы в отсутствие щелочного активатора поверхность получаемого углеродного продукта возрастает от 5 до $70 \mathrm{~m}^{2} / \Gamma$ при подъеме температуре от 300 до $800{ }^{\circ} \mathrm{C}$.

Щелочная термоактивация лигнина способствует значительному развитию пористой структуры углеродных продуктов. Под воздействием гидроксидов калия и натрия происходит значительное увеличение 
удельной поверхности и общего объема пор. Наиболее высокой удельной поверхностью обладают активные угли, полученные при соотношении лигнин : щелочь $=1: 3$. Максимальная величина удельной поверхности $\left(2680 \mathrm{~m}^{2} / \Gamma\right)$ достигнута при активации исходного лигнина гидроксидом калия.

Варьирование содержания щелочи в исходной смеси при постоянстве других параметров процесса активации приводит к изменению основных текстурных характеристик получаемых активных углей, таких как удельная поверхность, объем и размер пор. Данные по влиянию концентрации щелочи на характеристики активных углей, полученных термощелочной активацией лигнина соломы, приведены в таблице 1. С увеличением количества вводимого щелочного агента, наряду с ростом удельной поверхности происходит увеличение суммарного объема пор активных углей. При использовании КОН максимальная величина объема пор достигает $1,35 \mathrm{~cm}^{3} / \Gamma$, а при активации $\mathrm{NaOH}-1,39 \mathrm{~cm}^{3} / \Gamma$.

Ширина микропор в получаемых активных углях колеблется в интервале 1,7-2,4 нм. Величина сорбции бензола и водорода возрастает с увеличением удельной поверхности и объема пор.

Изотермы адсорбции азота на образцах активных углей, полученных при различном соотношении лигнин/КОН (рис. 1) по форме и виду соответствуют изотермам 1 типа, что позволяет отнести их к пористым материалам с относительно однородным распределением микропор.

Вид изотермы для образца 3, полученного при соотношении лигнин/КОН $1: 3$, свидетельствует о возросшей неоднородности пор по форме и размерам [11]. При этом увеличение общего объема пор сопровождается возрастанием среднего размера микропор для образца 3 до значений 2,0-2,25 нм, а для образцов 1 и 2 средний диаметр пор не превышает 1,8-1,9 нм.

Сравнение величин удельных поверхностей карбонизованных углей из лигнина до и после обработки щелочами указывает на то, что щелочная термоактивация улучшает пористость не только за счет образования новых пор, но и развивает существующие $[6,8,9]$. Присутствие катионов (K, Na) оказывает значительное влияние на направление термодеструкции, в частности, на образование газообразных веществ в результате частичной газификации $[12,13]$.

Развитие пористости в УМ, полученных карбонизацией и щелочной активацией лигнина, подтверждено методом сканирующей электронной микроскопии (рис. 2).

Таблица 1. Характеристики углеродных материалов, полученных термощелочной активацией лигнина КОН и $\mathrm{NaOH}$ при $800{ }^{\circ} \mathrm{C}$ (скорость нагрева $5{ }^{\circ} \mathrm{C} /$ мин)

\begin{tabular}{c|c|c|c|c|c}
\hline $\begin{array}{c}\mathrm{N} \\
\text { п/п }\end{array}$ & $\begin{array}{c}\text { Природа } \\
\text { щелочи }\end{array}$ & $\begin{array}{c}\text { Весовое соотношение } \\
\text { лигнин /щелочь }\end{array}$ & $\begin{array}{c}\text { Удельная } \\
\text { поверхность, } \mathrm{M}^{2} / \Gamma\end{array}$ & $\begin{array}{c}\text { Объем пор, } \mathrm{cm}^{3} / \Gamma \\
\text { Средний диаметр пор, } \\
\text { нм }\end{array}$ \\
\hline 1 & $\mathrm{KOH}$ & $1: 1$ & 1372 & 0,68 & 1,71 \\
2 & $\mathrm{KOH}$ & $1: 2$ & 1948 & 0,85 & 1,82 \\
3 & $\mathrm{KOH}$ & $1: 3$ & 2628 & 1,35 & 2,25 \\
4 & $\mathrm{NaOH}$ & $1: 1$ & 964 & 0,43 & 1,74 \\
5 & $\mathrm{NaOH}$ & $1: 2$ & 1386 & 0,63 & 1,88 \\
6 & $\mathrm{NaOH}$ & $1: 3$ & 2317 & 1,39 & 2,40 \\
\hline
\end{tabular}

Рис. 1. Изотермы адсорбции $\mathrm{N}_{2}$ при 77 К на образцах УМ, полученных термообработкой при $800{ }^{\circ} \mathrm{C}$ смесей лигнин/КОН при соотношениях $1: 1$ (1), $1: 2$ (2), $1: 3$ (3)

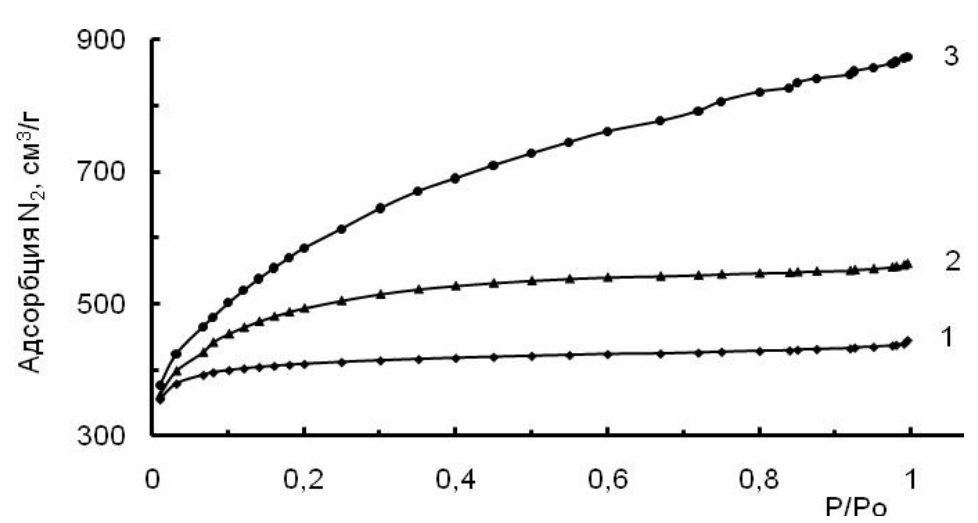




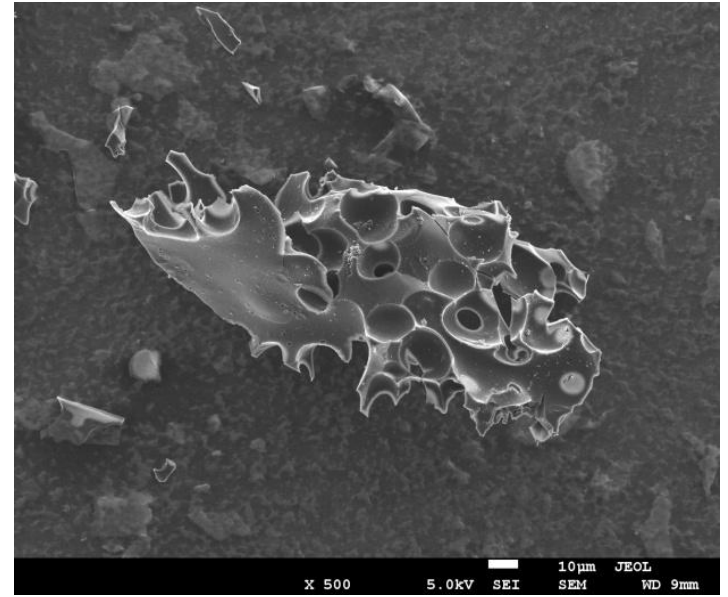

A

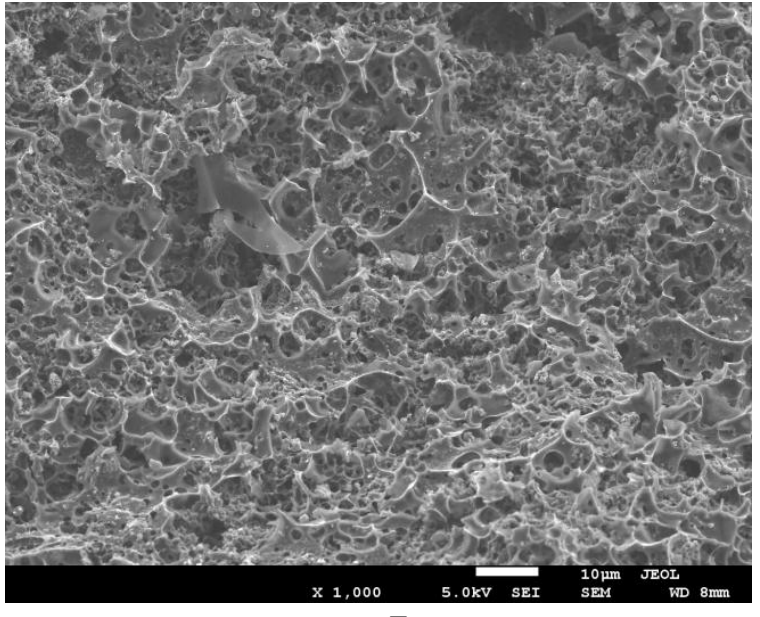

Б

Рис. 2. Микрофотографии образцов карбонизованного (А), а затем активированного КОН (Б) лигнина соломы при увеличении в 500 и 1000 раз соответственно (температура обработки $800{ }^{\circ} \mathrm{C}$ )

Образец карбонизованного лигнина (рис. 2А) представляет собой затвердевший стекловидный материал с плотным конгломератом частиц, где отчетливо различимы зародыши пор, размер которых значительно меньше $10 \mu$ м. Из микрофотографии образца А следует, что значительное количество пор генерируется уже в ходе процесса карбонизации. Микрофотография термообработанного в присутствии КОН лигнина (рис. 2Б) демонстрирует выраженную «вспененную» структуру. Хотя микропоры и мезопоры остаются невидимыми, приведенные снимки способны передать наблюдаемую форму и локализацию наиболее крупных пор на поверхности углеродного материала: диаметр сферических отверстий, достаточно равномерно распределенных на поверхности активированного УМ, не превышает 0,5-1,0 мкм. Причем в ходе активации карбонизованного лигнина КОН формируются более однородные поры меньшего диаметра, чем при активации $\mathrm{NaOH}$.

Согласно данным проведенного термогравиметрического анализа, термическое разложение лигнина соломы происходит в широком температурном диапазоне - от 168 до $650{ }^{\circ} \mathrm{C}$. Начало термохимических превращений лигнина наблюдается уже при невысоких температурах. Как видно из приведенного на рисунке 3 профиля разложения лигнина, уже при $168^{\circ} \mathrm{C}$ наблюдается небольшой максимум скорости потери массы на кривой ТГ, а к $200{ }^{\circ} \mathrm{C}$ потеря массы вещества достигает примерно $10 \%$.

При повышенных температурах снижение массы лигнина происходит в результате потери низкомолекулярных летучих веществ, которые, вероятно, образуются в результате распада кислородсодержащих функциональных групп и реакций дегидратации.

Интенсивный распад лигнина происходит в интервале температур 200-420 ㄷ. В этом температурном интервале в результате деструкции фрагментов лигнина выделяется значительное количество летучих веществ.Основные максимумы скорости потери массы образца наблюдаются при температурах 186,230 и $330{ }^{\circ} \mathrm{C}$.

Процесс интенсивной потери массы завершается к $500{ }^{\circ} \mathrm{C}$ и составляет около $50 \%$. При дальнейшем нагреве от 600 до $700{ }^{\circ} \mathrm{C}$ процесс потери массы существенно замедляется.

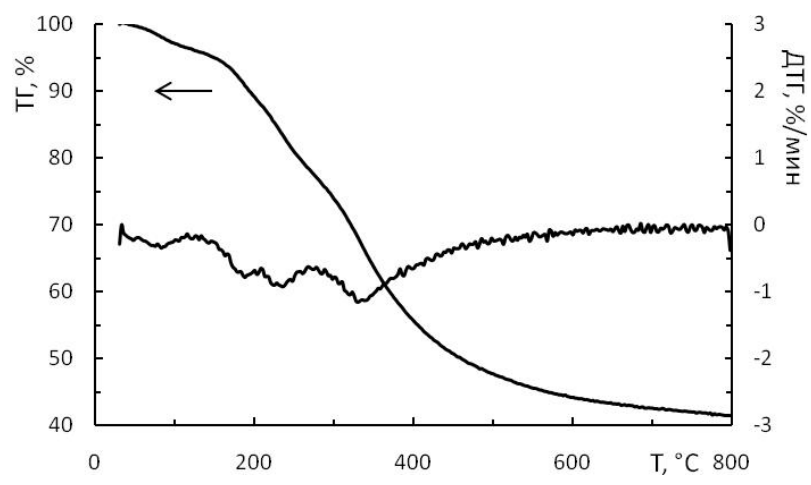

Рис. 3. Профиль терморазложения лигнина соломы в интервале температур $30-800{ }^{\circ} \mathrm{C}$ 
Установлено, что нагрев лигнина до $800{ }^{\circ} \mathrm{C}$ сопровождается увеличением содержания углерода в карбонизованных продуктах с 62 до 87,9 вес. \%, а содержание водорода и кислорода, напротив, уменьшается с 5,5 до 1,9 и с 31,9 до 6,8 вес. \% соответственно.

Было изучено влияние предварительной карбонизации лигнина $\left(800{ }^{\circ} \mathrm{C}\right.$, скорость нагрева $1{ }^{\circ} \mathrm{C} / \mathrm{Mин)}$ и последующей щелочной активации карбонизованных продуктов на текстурные характеристики получаемых углеродных материалов.

В результате структурного упорядочивания углеродного каркаса лигнина в процессе карбонизации снижается его реакционная способность к щелочному воздействию. Представленные в таблице 2 данные свидетельствуют о том, что образцы УМ, полученные активацией КОН предварительно карбонизованного при $800{ }^{\circ} \mathrm{C}$ лигнина, характеризуются менее развитой удельной поверхностью и объемом пор по сравнению с с образцами, полученными термощелочной активацией исходного лигнина.

Увеличение содержания гидроксида калия в смеси с карбонизованным при $800{ }^{\circ} \mathrm{C}$ лигнином от $1: 1$ до $1: 4$ приводит к росту удельной поверхности УМ с 749 до 2007 м²/г и общего объема пор с 0,349 до $0,972 \mathrm{~cm}^{3} / г$. Однако эти образцы уступают по величине удельной поверхности и объема пор УМ, полученным термощелочной активацией исходного лигнина.

Характер изотерм адсорбции $\mathrm{N}_{2}$, на УМ, полученных активацией КОН карбонизованного лигнина (рис. 4) свидетельствует о наличии развитой микропористой структуры в этих образцах. УМ из карбонизованного лигнина имеют более узкое распределение пор по ширине и более высокое соотношение объема микропор к общему объему пор $(0,54-0,69)$ по сравнению с УМ, полученными термощелочной активацией исходного лигнина.

Таким образом, предварительная карбонизация лигнина при $800^{\circ} \mathrm{C}$ позволяет направить процесс щелочной активации УМ на формирование более однородной микропористой текстуры с долей микропор 70$80 \%$ и размером $\leq 2$ нм.

В процессе термощелочной активации лигнина достигается лучшее развитие удельной поверхности и общей пористости, чем при использовании карбонизованного продукта за счет более высокой реакционной способности щелочного агента по отношению к О-содержащим функциональным группам лигнина. Снижение количества функциональных групп, играющих, по мнению $[8,14]$ важную роль в развитии пористости в ходе щелочной активации, приводит к уменьшению удельной поверхности и пористости получаемого УМ.

Изменение состава функциональных групп при термообработке лигнина было изучено методом FTIRспектроскопии. В области 3600-430 см-1 спектра исходного лигнина (рис. 5, кривая 1) наблюдается много полос поглощения (п.п.), характеризующих присутствие значительного числа кислородсодержащих функциональных групп. Интенсивное поглощение в области $3440 \mathrm{~cm}^{-1}$ указывает на наличие гидроксильных ОНалифатических и ароматических групп спиртов и фенолов. Полосы поглощения при 1600, 1510, $1460 \mathrm{~cm}^{-1}$ относятся к скелетным колебаниям ароматических фрагментов на основе гидроксифенилпропановых структурных единиц лигнина [15, 16]. Наличие п.п. при 2850, 1460 и 1033 см-1 обусловлено валентными и деформационными колебаниями связей в метоксильных $\mathrm{O}-\mathrm{CH}_{3}$ группах. Таким образом, спектр исходного лигнина демонстрирует присутствие значительного количества карбоксильных $\mathrm{O}-\mathrm{C}=\mathrm{O}$, карбонильных $\mathrm{C}=\mathrm{O}\left(\sim 1700 \mathrm{~cm}^{-1}\right)$,

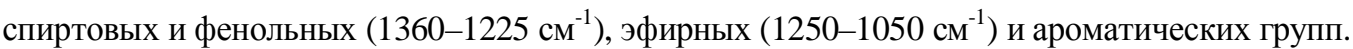

Карбонизация лигнина при $800{ }^{\circ} \mathrm{C}$ приводит к практически полному исчезновению в ИК-спектре полос поглощения, соответствующих алифатическим, спиртовым, эфирным и карбоксильным группам (рис. 5, кривая 2). Сохранение интенсивного широкого поглощения в области $3400 \mathrm{~cm}^{-1}$ может быть обусловлено наличием фенольных групп и адсорбированной воды. Во всех карбонизованных при разных температурах образцах лигнина присутствуют п.п. при $1600 \mathrm{~cm}^{-1}$, отвечающая колебаниям C=C связей в ароматических фрагментах.

Таблица 2. Текстурные характеристики УМ из лигнина соломы, предварительно карбонизованного при $800{ }^{\circ} \mathrm{C}$, затем активированного КОН*

\begin{tabular}{c|c|c|c|c|c}
\hline № & $\begin{array}{c}\text { Весовое соотноше- } \\
\text { ние лигнин/КОН }\end{array}$ & $\begin{array}{c}\text { Удельная } \\
\text { поверхность, } \mathrm{M}^{2} / \Gamma\end{array}$ & Объем пор, $\mathrm{cm}^{3} / \Gamma$ & $\begin{array}{c}\text { Объем } \\
\text { микропор, } \mathrm{cm}^{3} / \Gamma\end{array}$ & $\begin{array}{c}\text { Ширина пор, } \\
\text { нм }\end{array}$ \\
\hline 1 & $1: 1$ & 749 & 0,35 & 0,29 & 1,70 \\
2 & $1: 2$ & 1413 & 0,69 & 0,54 & 1,84 \\
3 & $1: 3$ & 1615 & 0,94 & 0,69 & 1,93 \\
4 & $1: 4$ & 2007 & 0,97 & 0,63 & 1,94 \\
\hline
\end{tabular}

* Рассчитаны из изотерм адсорбции азота при 77 К по методу БЭТ. 


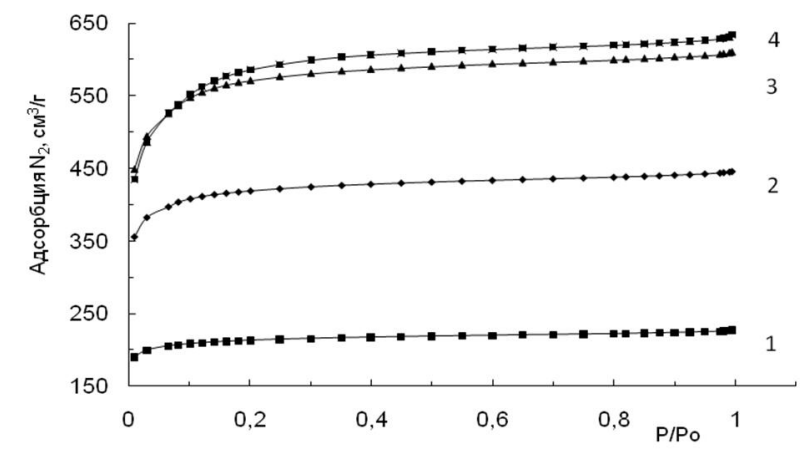

Рис. 4. Изотермы адсорбции азота на образцах УМ, полученных активацией КОН карбонизованного при $800{ }^{\circ} \mathrm{C}$ лигнина при соотношениях лигнин/ КОН $1: 1$ (1), $1: 2$ (2), $1: 3$ (3), $1: 4(4)$

Присутствующие в лигнине кислородсодержащие функциональные группы играют важную роль в развитии пористости при последующей активации КОН. Предполагается, что они взаимодействуют с КОН с образованием фенолятов, карбоксилатов калия и т.п., которые подвергаются термическому распаду с образованием газообразных соединений ( $\mathrm{CO}_{2}, \mathrm{CO}$ и др.), способствуя развитию пористой структуры углеродного материала [17, 18].

В карбонизованном при $800{ }^{\circ} \mathrm{C}$ лигнине остается мало кислородсодержащих групп, склонных взаимодействовать со щелочами и участвовать в процессе формирования пористой структуры УМ при термообработке. Как следует из приведенных в таблице 2 данных, только при высоких отношениях лигнин/КОН, $(1: 3-1: 4)$, достигаются условия, приводящие к развитию пористости в карбонизованном образце, вероятно, за счет эффекта каталитической газификации $[17,19]$.

При щелочном активировании карбонизованного лигнина развитие пористости может происходить и с участием металлического калия, образующегося в результате реакций КОН с углеродом при повышенной температуре. Как известно, калий может внедряться в угольную микроструктуру за счет интеркалирования между ароматическими слоями, повышая реакционную способность углерода в реакциях газификации [14, 20].

Тем не менее, предварительная карбонизация лигнина делает углеродный продукт менее восприимчивым к термощелочной активации.

Проведено сопоставление свойств пористых углеродных материалов, полученных термообработкой лигнина соломы, в адсорбции $\mathrm{H}_{2}$ при 77 К и давлении 6,5 МПа и бензола при 298 К (табл. 3).

Из полученных данных следует, что сорбционная активность пористых углеродных материалов коррелирует с величинами общего объема пор и удельной поверхности УМ. При этом наиболее заметной сорбционной емкостью обладали образцы, полученные термощелочной активацией при соотношении лигнин/щелочь 1:3. При использовании КОН величина сорбционной емкости УМ по водороду и бензолу составляла $2,8 \%$ вес. и 900 мг/г, соответственно, а в случае $\mathrm{NaOH}-3,3 \%$ вес. и 830 мг/ г.

Максимальная сорбционная емкость по $\mathrm{H}_{2}(2,8 \%$ вес.) УМ, полученного термоактивацией предварительно крабонизованного лигнина при отношении лигнин/КОН $1: 4$, совпадает с сорбционной емкостью УМ, полученного термощелочной активацией лигнина при соотношении лигнин/КОН $1: 3$.

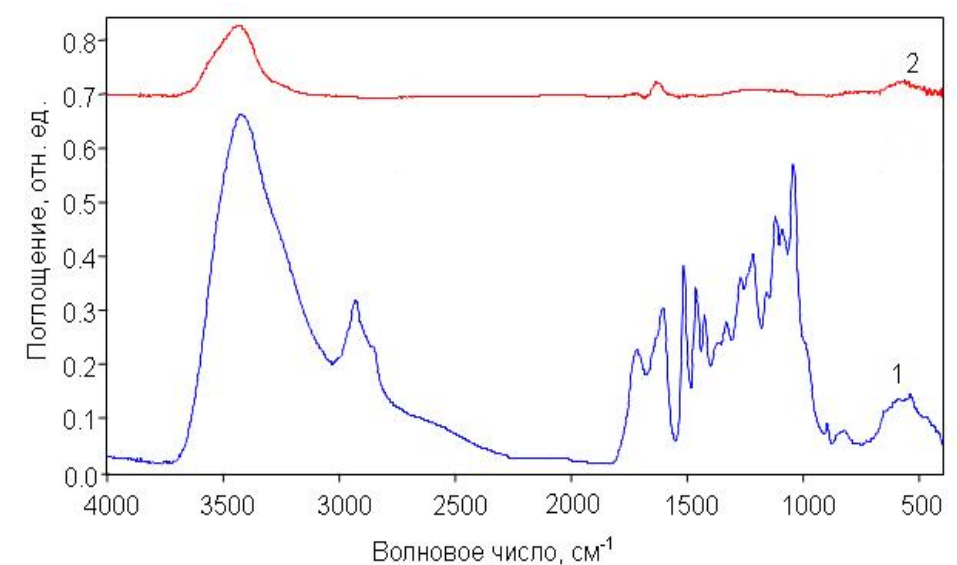

Рис. 5. ИК-спектр образцов лигнина соломы до (1) и после (2) карбонизации при $800{ }^{\circ} \mathrm{C}(0,5$ ч, аргон) 
Таблица 3. Сорбционные свойства УМ из лигнина соломы

\begin{tabular}{|c|c|c|c|c|c|c|}
\hline № & $\begin{array}{c}\text { Природа } \\
\text { щелочи }\end{array}$ & $\begin{array}{l}\text { Весовое отношение } \\
\text { лигнин/щелочь }\end{array}$ & $\begin{array}{c}\text { Удельная } \\
\text { поверхность, } \\
\text { м²/г }^{2}\end{array}$ & $\begin{array}{c}\text { Объем пор, } \\
\mathrm{cm}^{3} / \Gamma\end{array}$ & $\begin{array}{c}\text { Сорбция } \mathrm{H}_{2}, \% \\
\text { вес. }\end{array}$ & $\begin{array}{c}\text { Сорбция } \\
\text { бензола, мг/г }\end{array}$ \\
\hline $1 *$ & \multirow{3}{*}{ КОН } & $1: 1$ & 1372 & 0,68 & 2,2 & 472,0 \\
\hline $2 *$ & & $1: 2$ & 1948 & 0,85 & 2,4 & 503,7 \\
\hline $3 *$ & & $1: 3$ & 2628 & 1,35 & 2,8 & 903,1 \\
\hline $4^{*}$ & \multirow{3}{*}{$\mathrm{NaOH}$} & $1: 1$ & 964 & 0,43 & 1,9 & 283,1 \\
\hline $5^{*}$ & & $1: 2$ & 1386 & 0,63 & 2,0 & 283,0 \\
\hline $6^{*}$ & & $1: 3$ & 2317 & 1,39 & 3,3 & 830,9 \\
\hline $7 * *$ & \multirow{4}{*}{$\mathrm{KOH}$} & $1: 1$ & 749 & 0,35 & 1,7 & - \\
\hline $8 * *$ & & $1: 2$ & 1413 & 0,69 & 2,4 & - \\
\hline $9 * *$ & & $1: 3$ & 1615 & 0,94 & 2,6 & - \\
\hline $10 * *$ & & $1: 4$ & 2007 & 0,97 & 2,8 & - \\
\hline
\end{tabular}

Примечание: * получены термощелочной активацией лигнина при $800{ }^{\circ} \mathrm{C}$. ** получены термощелочной активацией при $800{ }^{\circ} \mathrm{C}$ продукта карбонизации лигнина.

\section{Заключение}

С использованием физико-химических методов исследования показано, что термощелочная активация лигнина, выделенного из соломы пшеницы, способствует развитию в получаемых углеродных материалах удельной поверхности до $2680 \mathrm{~m}^{2} / \Gamma$ и суммарного объема пор до 1,39 $\mathrm{cm}^{3} / \Gamma$. Установлено, что текстурные характеристики и сорбционные свойства в отношении $\mathrm{H}_{2}$ и бензола определяются соотношением лигнин : щелочь, природой щелочи ( $\mathrm{KOH}, \mathrm{NaOH})$, условиями термоактивации. Показано, что предварительная карбонизация лигнина в инертной атмосфере при $800{ }^{\circ} \mathrm{C}$ способствует при последующей термощелочной активации формированию микропористых материалов (доля микропор - 73-78\%) с узким распределением пор по размерам (1,7-1,9 нм).

Полученные углеродные материалы обладают высокой сорбционной емкостью по бензолу (до 900 мг/г) и водороду (до 3,3\% вес.). Микропористые сорбенты имеют перспективы использования в качестве углеродных сит для разделения газообразных смесей, а также сорбентов для очистки газов и воды.

\section{Список литературы}

1. Dizhbite T., Zakis G., Kizima A., Lazareva E., Rossinskaya G., Jurkjane V., Telysheva G., Viesturs U. Lignin a useful bioresourse for the production of sorption-active materials // Bioresour. Technol. 1999. Vol. 67. Pp. 221-228.

2. Khezami L., Chetouani A., Taouk B., Capart R. Production and characterisation of activated carbon from wood component in powder cellulose, lignin, xylan // Powder Technol. 2005. Vol. 157. Pp. 48-56.

3. Kuznetsov B.N., Shchipko M.L. The conversion of wood lignin to char materials in a fluidized bed of Al-Cu-Cr oxide catalysts // Bioresour. Technol. 1995. Vol. 52. Pp. 13-19.

4. Suhas Carrot P.J.M., Ribeiro Carrot M.M.L. Lignin - from natural adsorbent to activated carbon: A review // Bioresource Technology. 2007. Vol. 98. Pp. 2301-2312.

5. Baklanova O.N., Plaksin G.V., Drozdov V.A., Duplyakin V.K., Chesnokov N.V., Kuznetsov B.N. Preparation of microporous sorbents from cedar nutshells and hydrolytic lignin // Carbon. 2003. Vol. 42. Pp. 1793-1800.

6. Hayashi J., Muroyama K., Gomes V.C., Watkinson A.P. Fractal dimensions of activated carbon prepared from lignin by chemical activation // Carbon. 2002. Vol. 40. Pp. 630-632.

7. Guo Yu., Yu K., Wang Z., Xu H. Effects of activation condition on preparation of porous carbon from rice husk // Carbon. 2000. Vol. 41. Pp. 1645-1648.

8. Babel K., Jurewicz K. KOH activated lignin based nanostructured carbon exhibiting high hydrogen electrosorption // Carbon. 2008. Vol. 46. Pp. 1948-1956.

9. Zou Y., Han B.-X. Preparation of activated carbons from Chinese coal and hydrolysis lignin // Adsorp. Sci. Technol. 2001. Vol. 19. Pp. 59-72.

10. Strezov V., Patterson M., Zymla V., Fisher K., Evans T.J., Nelson P.F Fundamental aspects of biomass carbonization // J. Appl. Pyrolysis. 2007. Vol. 79. Pp. 91-100.

11. Грэг С., Синг К. Адсорбция, удельная поверхность, пористость. М., 1984. 306 с.

12. Huidobro, A.C. Pastor, F. Rodriguez-Reinoso. Preparation of activated carbon cloth from viscous rayon: Part IV. Chemical activation // Carbon. 2001. Vol. 39, N3. Pp. 389-398.

13. Hayashi J., Kazehaya A., Muroyama K., Watkinson A.P. Preparation of activated carbons from lignin by chemical activation // Carbon. 2000. Vol. 38. Pp. 1873-1878.

14. Lillo-Rodenas M.A., Marco-Lozar J.P., Cazorla-Amoros D., Linares-Solano A. Activated carbons prepared by pyrolysis of mixtures of carbon precursor/alkaline hydroxide // J. Anal. Appl. Pyrolysis. 2007. Vol. 80. Pp. 166-174. 
15. Карманов А.П., Деркачева О.Ю. Применение ИК-Фурье спектроскопии для исследования лигнинов травянистых растений // Химия растительного сырья. 2012. №1. С. 61-70.

16. Хергерт Г.Л. ИК-спектры лигнина. М., 1975. 632 с.

17. Rui-Qin Sun, Lin-Bing Sun, Yuan Chun, Qin-Hua Xu. Catalytic performance of porous carbons obtained by chemical activation // Carbon. 2008. Vol. 46. Pp. 1757-1764.

18. Lillo-Rodenas M.A., Juan-Juan J., Cazorla-Amoros D., Linares-Solano A. About reaction occurring during chemical activation with hydroxides // Carbon. 2004. Vol. 42. Pp. 1371-1373.

19. Kubo S., Uraki Y., Sano Y. Catalytic graphitization of hardwood acetic acid lignin with nickel acetate // J. Wood Sci. 2003. Vol. 49. Pp. 188-192.

20. Xue R., Shen Z. Formation of graphite-potassium intercalation compounds during activation of MCMB with KOH // Carbon. 2003. Vol. 41. Pp. 1851-1864.

Поступило в редакиию 14 ноября 2013 г.

Mikova N.M. ${ }^{l}$, Ivanov I.P. ${ }^{l}$, Chesnokov N.V. ${ }^{1,2}$, Kuznetsov B.N. ${ }^{1,3^{*}}$ THE STUDY OF THERMAL-ALKALINE ACTIVATION OF LIGNIN FROM WHEAT STRAW AND PROPERTIES OF OBTAINED ACTIVE CARBONS

${ }^{I}$ Institute of Chemistry and Chemical Technology SB RAS, K. Marksa st., 42, Krasnoyarsk (Russia)

${ }^{2}$ Krasnoyarsk scientific centre, Krasnoyarsk (Russia)

${ }^{3}$ Siberian Federal University, Svobodnyi ave., 79, Krasnoyarsk (Russia)

The influence of thermal treatment conditions of lignin isolated from wheat straw on structure and adsorption properties of active carbons (AC) was investigated. Chemical activation of lignin by $\mathrm{KOH}$ and $\mathrm{NaOH}$ promotes the development of specific surface area of obtained carbons up to $2680 \mathrm{~m}^{2} / \mathrm{g}$ and porous volume $1,35-1,39 \mathrm{~cm}^{3} / \mathrm{g}$. The preliminary carbonization of lignin at $800{ }^{\circ} \mathrm{C}$ decreases the ability of obtained carbons to alkaline activation (their surface area $\leq 2000 \mathrm{~m}^{2} / \mathrm{g}$ ), but favorites the formation of micropores carbons with narrow distribution of pores size (1,7-1,9 nm). Produced AC possess a high sorption activity with respect to benzene and $\mathrm{H} 2$.

Keywords: straw lignin, carbonization, alkaline activation, active carbon, porosity, adsorption properties.

\section{References}

1. Dizhbite T., Zakis G., Kizima A., Lazareva E., Rossinskaya G., Jurkjane V., Telysheva G., Viesturs U. Bioresour. Technol., 1999, vol. 67, pp. 221-228.

2. Khezami L., Chetouani A., Taouk B., Capart R. Powder Technol., 2005, vol. 157, pp. 48-56.

3. Kuznetsov B.N., Shchipko M.L. Bioresour. Technol., 1995, vol. 52, pp. 13-19.

4. Suhas Carrot P.J.M., Ribeiro Carrot M.M.L. Bioresource Technology, 2007, vol. 98, pp. 2301-2312.

5. Baklanova O.N., Plaksin G.V., Drozdov V.A., Duplyakin V.K., Chesnokov N.V., Kuznetsov B.N. Carbon, 2003, vol. 42, pp. 1793-1800.

6. Hayashi J., Muroyama K., Gomes V.C., Watkinson A.P. Carbon, 2002, vol. 40, pp. 630-632.

7. Guo Yu., Yu K., Wang Z., Xu H. Carbon, 2000, vol. 41, pp. 1645-1648.

8. Babel K., Jurewicz K. Carbon, 2008, vol. 46, pp. 1948-1956.

9. Zou Y., Han B.-X. Adsorp. Sci. Technol., 2001, vol. 19, pp. 59-72.

10. Strezov V., Patterson M., Zymla V., Fisher K., Evans T.J., Nelson P.F. J. Appl. Pyrolysis, 2007, vol. 79, pp. 91-100.

11. Greg S., Sing K. Adsorbtsiia, udel'naia poverkhnost', poristost'. [Adsorption, the specific surface area, porosity]. Moscow, 1984, 306 p. (in Russ.).

12. Huidobro, A.C. Pastor, F. Rodriguez-Reinoso. Carbon, 2001, vol. 39, no. 3, pp. 389-398.

13. Hayashi J., Kazehaya A., Muroyama K., Watkinson A.P. Carbon, 2000, vol. 38, pp. 1873-1878.

14. Lillo-Rodenas M.A., Marco-Lozar J.P., Cazorla-Amoros D., Linares-Solano A. J. Anal. Appl. Pyrolysis, 2007, vol. 80, pp. 166-174.

15. Karmanov A.P., Derkacheva O.Iu. Khimiia rastitel'nogo syr'ia, 2012, no. 1, pp. 61-70.

16. Khergert G.L. IK-spektry lignina. [IR spectra lignin]. Moscow, 1975, 632 p. (in Russ.).

17. Rui-Qin Sun, Lin-Bing Sun, Yuan Chun, Qin-Hua Xu. Carbon, 2008, vol. 46, pp. 1757-1764.

18. Lillo-Rodenas M.A., Juan-Juan J., Cazorla-Amoros D., Linares-Solano A. Carbon, 2004, vol. 42, pp. 1371-1373.

19. Kubo S., Uraki Y., Sano Y. J. Wood Sci., 2003, vol. 49, pp. 188-192.

20. Xue R., Shen Z. Carbon, 2003, vol. 41, pp. 1851-1864.

\footnotetext{
* Corresponding author.
} 